\title{
THE EFFECTS OF SMOKING LAWS ON SEATING ALLOCATIONS OF RESTAURANTS, BARS, AND TAVERNS
}

\author{
JOHN DUNHAM and MICHAEL L. MARLOW*
}

Supporters of smoking laws often argue that they do not harm restaurants, bars, and taverns and may even raise their profits. Opponents argue that owners cater to customer preferences regarding smoking and that laws mandating specific smoking policies will therefore negatively impact profits of some firms. This article tests hypotheses regarding how smoking laws affect seating allocations, using data from a nationwide survey of restaurant and bar owners. The empirical evidence indicates that smoking laws exert no significant effect on seating allocations. Firms are shown to allocate greater shares of seating to nonsmoking use when customers exhibit stronger preferences for such seating.

\section{INTRODUCTION}

Laws restricting smoking in restaurants have been enacted in 32 states. Supporters of these laws often argue that they do not harm firms and may even raise their profits. ${ }^{1} \mathrm{Re}$ cent studies, for instance, argue that outright bans on smoking in eating and drinking places have not adversely affected these establishments, suggesting that smoking bans either do not reduce demand or lower costs for firms, which offsets sales losses, thus leading to no adverse changes in profits. Opponents of smoking restrictions argue that owners cater to customer preferences re-

*This article is based on an earlier study that was conducted for Philip Morris Management Corporation. The authors thank William J. Boyes, Frank J. Chaloupka, and two anonymous referees for helpful comments.

Dunham: Manager of Fiscal Issues, Philip Morris Management Corporation, New York, New York, Phone 917-663-2835, Fax 917-663-5379, E-mail john120@idt.net

Marlow: Professor, Department of Economics, California Polytechnic State University, San Luis Obispo, California, Phone 805-756-1764, Fax 805-756-1473, E-mail mmarlow@calpoly.edu

1. Proponents of smoking bans also often argue that, absent such restrictions, taxpayers are forced to pick up part of the higher health care costs of smokers in Medicaid, Medicare and private insurance programs. However, Lee [1991a, 1991b] suggests that smoking bans can not be expected to lower this type of externality. See also a recent Congressional Research Service report for Congress [Gravelle and Zimmerman 1994], which argues that it is likely that passive smoke risk has been overestimated by the Occupational Safety and Health Administration. The July 1998 decision by U.S. District Judge William L. Osteen also concluded after five years of court proceedings that the EPA had wrongly labeled secondhand smoke a class A carcinogen and that the agency relied on faulty science to reach the conclusion it wanted. garding smoking. Some owners would find it profitable to allow smoking throughout their establishments, others to forbid all smoking, and still others to accommodate both smokers and nonsmokers by investing in partitions, designating areas, creating smoking patios or rooms, and/or investing in air filtration systems. They argue that laws that mandate specific smoking policies will therefore negatively impact profits of some firms.

Little economic research has been published on the effects of smoking laws on revenues of restaurants, bars, and taverns, and none has been directed toward the issue of smoking/nonsmoking seating allocations. ${ }^{2}$ This article provides a framework for examining how customer preferences influence smoking and nonsmoking seating allocations by owners - the primary policy that firms unilaterally adopt in their attempts to deal with the issue. Hypotheses regarding how smoking laws affect seating allocations are then tested using data from a nationwide survey of 1,300 restaurant, bar, and tavern owners. The empirical evidence indicates that smoking laws exert no significant effect on seating allocations.

\section{ECONOMIC MODEL AND TESTABLE HYPOTHESES}

Without legal restrictions, policies adopted by restaurants, bars, and taverns toward

2. See, for instance, M. K. Evans [unpublished data], Glantz and Smith [1994, 1997], and Sciacca and Ratliff [1998] for studies of the effects of smoking laws on revenues of restaurants. 
smoking are determined in much the same manner as decisions regarding menus, prices, and hours of operation. Profit-maximizing firms optimize on the basis of customer demand and costs. Decisions pertaining to smoking policies simply allocate the air space within firms between smoking and nonsmoking customers. ${ }^{3}$ The air space within an establishment is considered just like any other resource, and owners decide to cater solely to smokers, to nonsmokers, or to both by providing patrons with rights to smoke while accommodating others through smoking/ nonsmoking areas and air filtration systems. The choice depends on customer preferences and relative marginal costs. ${ }^{4}$ Predictably, market segmentation naturally evolves where firms cater more to smokers in markets dominated by smokers than in those markets dominated by nonsmokers.

There may also be broad differences between how owners of restaurants and bars or taverns allocate seating. Customers of restaurants are likely to prefer that owners adopt different accommodation strategies than would patrons of bars and taverns. Restaurant customers tend to dine in one location within firms, and therefore it is possible for owners to designate sections for smokers and nonsmokers, and this predictably leads to a relatively high allocation of nonsmoking seating. In contrast, customers of bars and taverns may prefer to participate in various activities (dining, drinking, listening to music, dancing, and playing pool, darts, and billiards) whereby they move to different locations within the establishment during their visit and interact with different patrons. It is relatively more difficult and therefore costly to designate areas for smokers and nonsmokers in bars and taverns, and this predictably leads to a relatively low allocation of nonsmoking seating. Moreover, because of the interactive atmosphere of bars and taverns, it is unlikely that all nonsmokers wish to remain sepa-

3. Lee [1991b] argues that owners of private establishments have an incentive to internalize externalities associated with smoking; see also Tollison and Wagner [1992] and Boyes and Marlow [1996].

4. Smoking policies may also be influenced by preferences of owners, managers, and employers, but it is unclear that their preferences would override those of customers when owners profit maximize and hire in competitive labor markets. rated from their smoking friends (and vice versa), and therefore many bar and tavern owners may find it relatively unprofitable (and unpopular) to segregate these two groups.

This reasoning leads to the testable hypothesis that the mix of smoking/nonsmoking seating is influenced by the smoking preferences of customers so that nonsmoking seating allocations are inversely related to the percentage of customers who smoke. It is also possible that the smoking characteristics of state populations may be a significant factor explaining whether state governments pass smoking restrictions. We expect that states with relatively few smokers are more likely to pass smoking laws.

\section{DESCRIPTION OF DATA}

Survey data collected by Roper Starch for the National Licensed Beverage Association is used to examine how smoking laws influence seating allocations. The survey was conducted by telephone interviews during the period of September 5-12, 1996. All interviewing was conducted from the Roper Starch central interviewing facility. The sample consisted of owners /managers of 1,300 randomly drawn restaurants (650) and bars or taverns (650) across the United States. Samples were drawn in a statistically random manner from national lists provided by Survey Sampling, Inc., a major supplier of survey samples to research organizations. To the extent that the Survey Sampling lists include most full-service restaurants and bars or taverns in the United States, the survey results are applicable to all such establishments with a maximum sampling error of approximately plus or minus four percentage points for each sample of establishments. The survey instrument was developed by Roper Starch and includes questions pertaining to seating allocations, attitudes toward smoking laws, strategies to deal with smoking/nonsmoking customers, revenues, and projections of effects of smoking laws on revenues.

\section{TESTING WHETHER SEATING ALLOCATIONS ARE INFLUENCED BY CUSTOMER PREFERENCES}

Selected summary statistics demonstrate that firms in the sample differentiate themselves by a number of characteristics, includ- 
ing chain affiliation, age, and size. The range of employment in bars and taverns is $0-158$ workers, and for restaurants it is $0-300$ workers. ${ }^{5}$ Firms also differentiate themselves on how they cater to smoking and nonsmoking preferences of customers. Allocations range from strict prohibition, mixes of smoking and nonsmoking seating, and smoking allowed throughout establishments. For restaurants, the average percentage of seating that is allocated to nonsmoking is $54 \%$, while for bars and taverns it is 5\%-this difference is consistent with expectations. Both types of establishments have cases where smoking is entirely prohibited, and both have cases where smoking is allowed throughout the establishment. Of owners / managers of restaurants who offer a nonsmoking seating section, more than twothirds indicate that this is a product of their own policy. For bars offering partial nonsmoking seating, more than half of managers / owners indicate that this is a result of their own policy. The data indicate that both complete and partial nonsmoking environments exist in private markets with and without smoking laws. ${ }^{6}$

Table I displays means and standard deviations associated with three variables: percent of seating allocated to nonsmoking use, percent of smokers in the adult population, and the percent change in the adult smoker population over 1989-95, and for three sam-

5. Zero workers means that the firm is entirely run by the owner and/or family.

6 . The data are limited in that they test the knowledge of owners about the source of the smoking law. There were many local smoking restrictions in place during the period when the survey was conducted; however, most of the more restrictive laws were put in place after 1996. ples: all states, states with a smoking law, and states without a smoking law. While the average nonsmoking seating allocation from states with and without a smoking law does not differ significantly, significant differences exist for the other two variables (significance at 5\% level). That is, states with smoking laws tend to have fewer smokers and tend to have much larger reductions in smoking populations.

Figure 1 displays distributions of the shares of seats devoted to nonsmoking in the states with and without smoking laws. For instance, $57 \%$ of firms in the states without smoking laws devote $0 \%-20 \%$ of their seating to nonsmoking use, as opposed to $62 \%$ of firms in states with smoking laws. Within this grouping, $52 \%$ of firms in states without smoking laws actually devote $0 \%$ of their seating to nonsmoking use, and 59\% of firms in states with smoking laws devote $0 \%$ of their seating to nonsmoking use. At the other extreme, $16 \%$ of firms in states without laws devote $81 \%-100 \%$, as opposed to $18 \%$ of firms in states with laws. Within this grouping, $14 \%$ of firms in states without smoking laws actually devote $100 \%$ of their seating to nonsmoking use, and $16 \%$ of firms in states with smoking laws devote $100 \%$ of their seating to nonsmoking use. Assuming that the distribution surrounding firms in no-law states is the expected distribution, the chisquare test indicates at the 5\% level that we cannot reject the hypothesis that the distribution surrounding firms in smoking law states does not differ significantly from that of firms in no-law states. Therefore, the distribution of the shares of nonsmoking seating does not appear to differ between these two samples. It is important to note that this

TABLE I

Means and Standard Deviations

\begin{tabular}{lccc}
\hline & $\begin{array}{c}\text { All States } \\
(\boldsymbol{n}=\mathbf{1 3 0 0})\end{array}$ & $\begin{array}{c}\text { States with Smoking Laws } \\
(\boldsymbol{n}=\mathbf{9 6 8})\end{array}$ & $\begin{array}{c}\text { States without Smoking Laws } \\
(\boldsymbol{n}=\mathbf{3 3 2})\end{array}$ \\
\hline Nonsmoking seating & 29.5 & 29.1 & 30.6 \\
(\% of total seating) & $(39.5)$ & $(39.9)$ & $(38.3)$ \\
Smokers & 21.6 & 20.8 & 23.8 \\
(\% of population) & $(3.2)$ & $(3.2)$ & $(2.0)$ \\
Smoker change & -2.1 & -2.9 & -.003 \\
$(\%$ change, 1989-95) & $(2.4)$ & $(2.2)$ & $(1.6)$ \\
\hline
\end{tabular}

Note: Standard deviations are displayed in parentheses below the means. 
FIGURE 1

\section{Non-Smoking Seating Distributions Law vs. No-Law Samples}

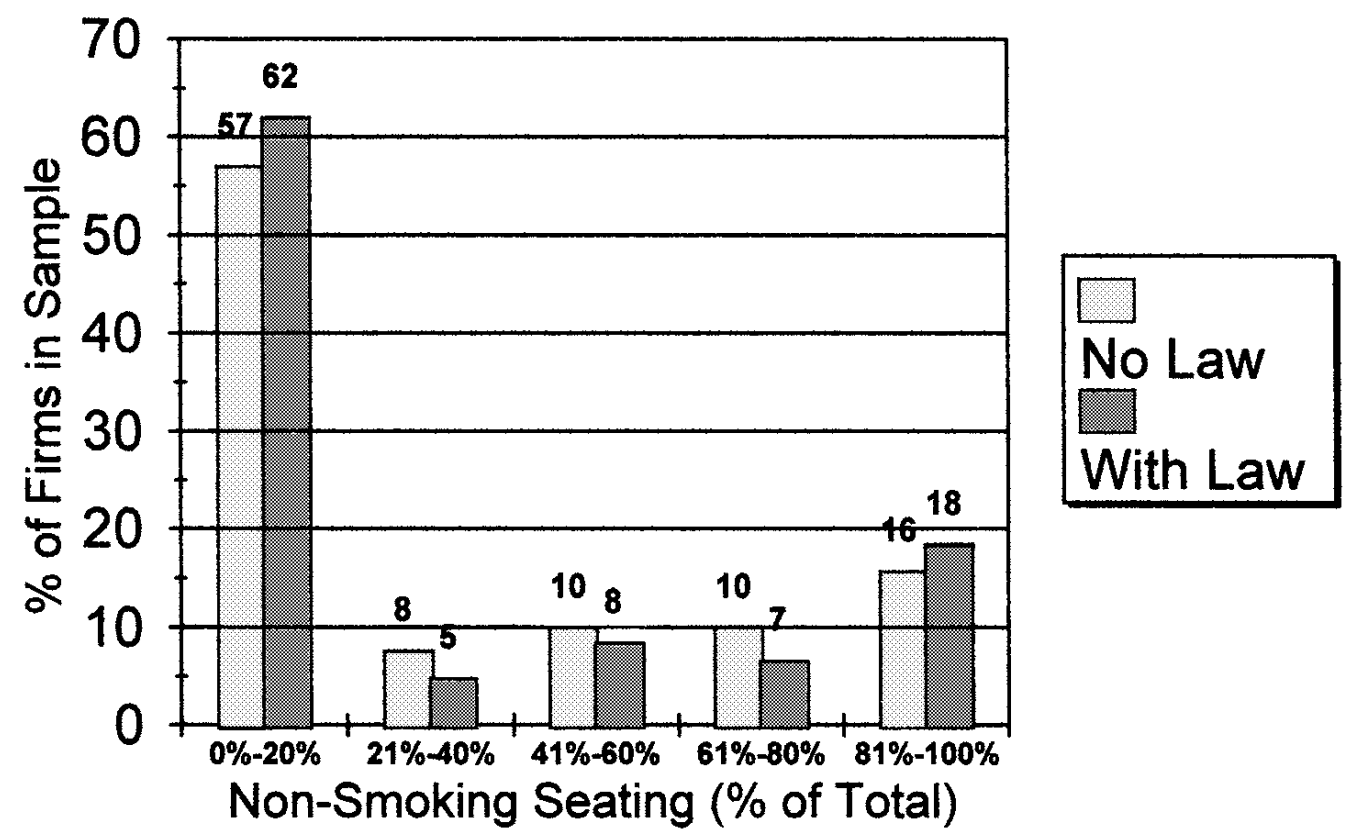

data set was developed in 1996 and may not reflect the implications of de facto complete smoking bans such as the one that now exists in California.

Many other factors may also influence allocations of seating into smoking/nonsmoking designations. The size of a firm (e.g., number of employees) may influence decisions when scale economies exist in catering to both smoking and nonsmoking populations. A positive relationship between firm size and nonsmoking seating allocations may occur if larger firms may more easily separate smokers from nonsmokers. Whether an establishment is a member of a corporate chain or an independent firm may also affect the allocation decision. Chain members may offer greater accommodation as an element in their overall corporate strategy. If this is the case, then chain members would offer greater nonsmoking seating allocations than independents. Years in business may also influence seating allocations, since established reputations may attract a different mix of customers, and there may be differential accommodation costs related to age of buildings. It is possible that older businesses may tend to accommodate less, given that their owners tend to cater to more established and stable customer bases than newer businesses.

Table II displays estimates from three regression equations. ${ }^{7}$ Column 1 contains estimates of an ordinary least squares regression of nonsmoking seating on smoking laws.

$$
N S_{i}=f\left(\text { Smoklaw }_{i}\right),
$$

where $N S_{i}=$ percentage of seating that is nonsmoking

$$
\begin{aligned}
\text { Smoklaw }_{i} & =1 \text { if smoking law present; } \\
& =0 \text { otherwise. }
\end{aligned}
$$

No significant relation is determined by this simple regression, thus indicating that smoking laws do not appear to influence seating allocations of owners.

In column 2 of Table II, we instrument for smoking laws with tobacco manufacturing in the state because there are various factors relating to the social acceptability of

7. Significant relations are assumed to be those meeting statistical significance at 5\% (two-tailed) levels or greater. 
TABLE II

Ordinary-Least-Squares Results

\begin{tabular}{|c|c|c|c|}
\hline Dependent Variable & $\begin{array}{c}\% \text { Nonsmoking } \\
\text { seating }\end{array}$ & Smoking Law & $\begin{array}{c}\% \text { Nonsmoking } \\
\text { Seating }\end{array}$ \\
\hline Constant & $\begin{array}{r}30.57^{a} \\
(14.10)\end{array}$ & $\begin{array}{r}0.76^{*} \\
(62.75)\end{array}$ & $\begin{array}{r}111.14^{a} \\
(9.09)\end{array}$ \\
\hline $\begin{array}{l}\text { Smoking law } \\
(\text { Yes }=1, \mathrm{No}=0)\end{array}$ & $\begin{array}{l}-1.47 \\
(-0.58)\end{array}$ & & \\
\hline Tobacco manufacturing & & $\begin{array}{l}-.0001^{*} \\
(-6.86)\end{array}$ & \\
\hline Smoking law instrument & & & $\begin{array}{l}-3.17 \\
(-0.31)\end{array}$ \\
\hline Smokers & & & $\begin{array}{l}-2.17^{a} \\
(-7.96)\end{array}$ \\
\hline$\%$ change in smokers & & & $\begin{array}{c}0.26 \\
(0.57)\end{array}$ \\
\hline $\begin{array}{l}\text { Chain member } \\
(\text { Yes }=1, \text { No }=0)\end{array}$ & & & $\begin{array}{r}5.68^{a} \\
(3.08)\end{array}$ \\
\hline Years in business & & & $\begin{array}{l}-0.09 \\
(-1.83)\end{array}$ \\
\hline Number of employees & & & $\begin{array}{r}0.26^{a} \\
(6.60)\end{array}$ \\
\hline $\begin{array}{l}\mathrm{Bar} \\
(\mathrm{Yes}=1, \mathrm{No}=0)\end{array}$ & & & $\begin{array}{l}-45.14^{a} \\
(-25.89)\end{array}$ \\
\hline Adjusted $R$-squared & 0.00 & 0.03 & 0.45 \\
\hline Mean dependent variable & 29.48 & 0.74 & 29.48 \\
\hline$F$-statistic & 0.34 & 47.02 & 155.95 \\
\hline Observations & 1,300 & 1,300 & 1,300 \\
\hline
\end{tabular}

Note: $t$-statistics in parentheses.

${ }^{\mathrm{a}}$ Significance at $1 \%$ level.

smoking that may influence the smoking law variable that are hypothesized to separately influence seating allocations as well. The presence of a tobacco manufacturing facility in a state serves as a good proxy for these factors, since these facilities tend to be concentrated in states where tobacco growing and employment make up a large part of the economy. States with a larger percentage of people involved in the tobacco industry may be less likely to pass severe restrictions on tobacco use in general. Equation (2) is estimated by ordinary least squares:

$$
\text { Smoklaw }_{i}=f\left(\text { Tobman }_{i}\right),
$$

where Tobman $_{i}=$ dollar value of state tobacco manufacturing in 1994 (\$M). The tobacco-manufacturing variable, which exerts a statistically significant and negative influence on the smoking law variable, indicates that states with sizeable tobacco manufacturing will tend to not pass smoking laws.
Ordinary-least-squares estimation of equation (3) tests the hypothesis that private markets allocate nonsmoking seating subject to the following variables: smoking law (instrument), incidence of smoking in the adult population, changes in smoking incidence, whether the firm is part of a corporate chain or independent, firm size, years in business, and whether the firm is a restaurant or a bar or tavern. ${ }^{8}$

$$
\begin{aligned}
& N S_{i}=f\left(\text { Smoklaw }_{i}, S 95_{i}, S 9589_{i},\right. \\
& \text { Chain } \left._{i}, \text { Years }_{i}, \text { Size }_{i}, \text { Bar }_{i}\right),
\end{aligned}
$$

8. Variables obtained outside of the survey are: smoking law is obtained from the Tobacco Institute's "State Smoking Restriction Laws" [unpublished data]; all other data obtained from the Center for Disease Control. The smoking rate data measure the prevalence of current cigarette smoking among adults, and are generated by the Behavioral Risk Factor Surveillance System. The tobacco manufacturing variable measures cash receipts from tobacco large enough to be separately reported by the Center for Disease Control. 
where $S 95_{i}$ is the percentage of adult population that smokes, $S 9589_{i}$ is the change in percentage of adult population that smokes from 1989 to 1995 , Chain $_{i}$ is 1 if firm is part of corporate chain; $=0$ otherwise Size $_{i}$ is the number of full- and part-time employees, Years $_{i}$ is the number of years in business, $B a r_{i}$ is 1 if bar or tavern; $=0$ if restaurant.

Equation (3) assumes that smoking laws do not directly influence smoking behavior in a way that would separately influence the owners' allocation of nonsmoking seating. A counter-hypothesis - that state smoking laws themselves may cause fewer citizens to smoke-implies a simultaneous equations bias in our estimation. However, while the intent of some smoking laws is to decrease smoking, the primary intent is to control smoking, and especially exposure to secondhand smoke, within restaurants, bars and taverns. ${ }^{9}$ While many advocates of smoking laws might also prefer that smoking decline outside of these establishments as well, this is clearly of secondary importance for these particular types of restrictions. Moreover, we are unable to test whether smoking laws lead to less smoking by customers (and therefore leads owners to allocate less seating to smokers) simply because this requires time-series data that is unavailable. Such data may become available in the future, but at this point we know of no other data that measures seating allocations and none that provides such a series over time.

It is also unclear that smoking laws would significantly affect smoking behavior because of less-than-perfect enforcement. Anecdotal evidence appears to suggest that those businesses that would be most adversely affected by smoking laws (i.e., those catering to relatively high numbers of smokers) would also prefer relaxed enforcement of smoking

9. Sciaca and Ratliff [1998], writing in the American Journal of Health Promotion, mention reduction in exposure of nonsmokers to ETS (environmental tobacco smoke) first in the reasons for why laws prohibiting smoking in restaurants are approved. They also suggest that these laws provide an additional incentive and a supportive environment for smokers to quit, but this reasoning appears secondary in importance. Moreover, California approved a total smoking ban in all restaurants and bars based on protection of employees from ETS, once again indicating that any effects on smoking behavior outside of these establishments to be secondary. laws. ${ }^{10}$ To the extent that this is true, smoking laws may not be particularly effective in lowering smoking-both within and outside restaurants, bars and taverns - and in this case may not be particularly effective in changing owners' allocation of nonsmoking seating. ${ }^{11}$

Estimation results of equation (3) are presented in the third column of Table II. ${ }^{12}$ The smoking law instrument does not exert a significant effect on seating allocations. The incidence of smoking in the adult population, however, exerts a negative and statistically significant effect on nonsmoking seating. That is, firms allocate less seating to nonsmoking use as the percentage of smokers rise in the population - a relationship consistent with expectations. Change in the nonsmoking population exerts no statistically significant influence on seating allocations. As hypothesized, affiliations with a chain and firm size are significantly and positively related to the percentage of nonsmoking seating. As hypothesized, years in business exert a negative effect on nonsmoking seating but is only significant at the $10 \%$ percent level. Finally, the dummy variable for bars and taverns exerts a significant and negative influence on seating allocations, as consistent with expectations.

That smoking laws are not significant determinants of nonsmoking seating deserves further discussion. The data for this analysis were developed in 1996, prior to the establishment of many highly restrictive local smoking ordinances. In the case where smoking is banned (and enforced) throughout establishments - or is limited so that it becomes extremely inconvenient to smoke-the results of the analysis will not apply. However, when smoking laws allow for the accommodation of both smokers and nonsmok-

10. Newspaper articles on the smoking ban in California, for example, document widespread civil disobedience; see, Blankstein [1998], Canto [1998], and Risling [1998].

11. Chaloupka and Saffer [1992] find no evidence that state-wide smoking bans in restaurants have any effect on smoking as measured by cigarette consumption.

12. We included cross-effects between numbers of employees and smoking law variables and between smoking law and bar variables, but neither exerted statistically significant effects. In addition, while it would be appropriate to control for intrastate correlation in our regressions, this is not possible given the small number of observations of many states. 
ers, states with relatively high percentages of nonsmokers also tend to have relatively high allocations of space devoted to nonsmoking uses. This suggests that, in many cases, smoking laws are enacted "after the fact" in the sense that they appear after the private market has already reallocated resources in profit-maximizing ways. That is, firms find it profitable to allocate more space to nonsmokers, as these customers become more important to their overall revenues. A smoking law will not alter allocation of space when firms themselves have already met smoking preferences of customers, provided that the laws do not mandate that nonsmoking space significantly exceed that provided voluntarily by owners. Of course, another interpretation may be that restrictive laws are simply not highly enforced and are therefore ineffective in altering nonsmoking space within restaurants, bars or taverns. ${ }^{13}$

\section{CONCLUSIONS}

Proponents of laws restricting smoking within restaurants, bars, and taverns argue that they are necessary based on the belief that owners will underallocate nonsmoking seating in their establishments. This article provides the following insights into this issue. First, in the absence of outright smoking bans, firms allocate greater shares of seating to nonsmoking use when their customers exhibit stronger preferences for such seating. In other words, the private market allocates air space resources within firms with or without smoking restrictions, and it is unlikely that removal of smoking laws would overturn this result. In fact, there is no evidence that smoking laws themselves affect the seating allocation decisions, thus indicating that private markets have already dealt effectively with the smoking issue in the sense that, in the absense of outright smoking bans, firms tend to voluntarily allocate in excess of government mandates or that enforcement of smoking laws is imperfect.

13. In this event, however, it would appear that if these laws were enforced, they would tend to lower profits of some owners.
Second, the article suggests that the continued decline of smokers as a share of the population will encourage the owners of hospitality establishments to allocate more space to nonsmoking customers. This reallocation arises because of the profit motive and appears to be an active process within the restaurant, bar, and tavern industries. Economic examination of the timing of these decisions - how quickly do owners reallocate their seating space to changes in numbers of nonsmokers-would be a useful addition to our research. At this point, however, timeseries data are unavailable that would allow us to examine the speed of seating reallocations by owners toward nonsmokers.

\section{REFERENCES}

Blankstein, Andrew. "Enforcement Clouds Issue of Smoking Ban," Los Angeles Times, September 21, 1998, 3.

Boyes, William J., and Michael L. Marlow. "The Public Demand for Smoking Bans." Public Choice, July 1996, 57-67.

Canto, Minerva, "Californians Puff on Despite Ban," Washington Post, September 24, 1998, Sec. A., p. 7.

Chaloupka, Frank J., and Henry Saffer. "Clean Indoor Air Laws and the Demand for Cigarettes." Contemporary Policy Issues, April 1992, 72-83.

Glantz, Stanton A., and Lisa R. A. Smith. "The Effect of Ordinances Requiring Smoke-Free Restaurants on Restaurant Sales." American Journal of Public Health, July 1994, 1081-85.

"The Effect of Ordinances Requiring SmokeFree Restaurants and Bars on Revenues: A Follow-Up." American Journal of Public Health, October 1997, 1687-93.

Gravelle, Jane G., and Dennis Zimmerman. "Cigarette Taxes to Fund Health Care Reform: An Economic Analysis." March 8, 1994, Congressional Research Service Report for Congress.

Lee, Dwight, R. "Environmental Economics and the Social Cost of Smoking." Contemporary Policy Issues, January 1991a, 83-91

"Government v. Coase: The Case of Smoking." Cato Journal, Spring 1991b, 151-65.

Risling, Greg. "Law Hasn't Completely Barred Smoking in Taverns. Los Angeles Times, September 23, 1998, A3.

Sciacca, John P., and Michael I. Ratliff. "Prohibiting Smoking in Restaurants: Effects on Restaurant Sales." American Journal of Health Promotion, January $1998,176-84$.

Tollison, Robert D., and Richard E. Wagner. The Economics of Smoking. Norwell, Mass: Kluwer Academic, 1992. 